meels on the cormen I introduced s diluted preparation of the ointment of red oxide of mercury within the ejelids; the child cried lustily, and the stimulated eje was rendered perhaps a little more moist, but no tears flowed upon the fids, or collected at the inner angle. This treatment was repeated on several occasions, and always with the same results, even when the tip of my finger was placed over the orifices of the lachrymal puncte, so as, if possible, to obstruct them.

On the 1st of July, little change having taken place in the opacities, about which the mother of the patient expressed much solicitude, a stronger stimulus (tinctura opii) was applied to the right conjunctiva, which then became red, and a clear colourless fluid of saltish taste gushed from the eye, and rolled upon the cheek; but although the child screamed with pain, its left eye and lachrymal gland preserved throughout a perfectly quiescent condition. About a week afterwards, the tinctura opii was applied to the latter, and it wept, its fellow being at the same time tearless. This treatment proved satisfactorily the presence of two lachrymal glands, and their ability to secrete tears under an extraordinary stimulation only.

The cause of their torpidity appears to me, at the present age of the patient, to be inexplicable. I believe this to be the first case recorded in which such an affection, uncomplicated by disease of the conjunctiva, has been congenital. The more common causes of a suppressed, or diminished secretion of tears, are-disease of the lachrymal gland; certain cases of amaurosis; the impaired nutrition of advanced life; violent grief; and closure of the lachrymal ducts.

Before concluding this communication, I must notice that Mr. Wardrop has related in the Lancet for Nor. 29th, 1853, a case of congenital dryness of the conjunctiva (xeroma), with insbility to weep, in consequence of the intimate adhesions of the eyelids to the globes obstructing the lachrymal ducts.

A similar condition is occasionally produced by chronic inflammation of the conjunctiva in the adult. Indeed, it is possible that Mr. Wardrop's case may have been the result of intra-uterine conjunctivitis.

Birmingham, January, 1854.

\section{A CASE OF DISLOCATION OF THE HEAD OF THE HUMERUS UPON THE DORSUM OF THE SCAPULA.}

By ROBERT DUNN, F.R.C.S., etc.

Mr. W IEst's case of dislocation of the os humeri upon the dorsum of the scapula, in the Association Joursal for Jan. 6th, is highly interesting, not merely on account of its rarity, but from the detail of how the accident occurred. Few such cases are to be found in the annals of British surgery. The very possibifity of their occurrence has been denied by so great a surgeon as Boyer. It has reminded me of an instance which came under my own observation many years ago; and I need offer no apology for placing it upon record. I communicated the particulars at the time to my much respected friend, the late Mr. Bransby $B$. Cooper, and he was regularly in the habit of relating the case to his class, in his surgical lectures at Guy's Hospital.

The case was that of an old woman, aged 60 years, living in Hen and Chicken Court, Fleet Street, who had fallen down in a fit, and to whom I had been called. Before I arrived, she bad recovered from the fit, but she complained to me of great pain in the shoulder, and of inability to move the arm. Upon a careful examination, which I was induced to make, from the appearance being 80 very different from what might have been expected from paralysis, or any other neuralgic affection, I soon perceived that the articulatory surface of the humerus had been thrown from the glenoid cavity of the scapula. Upon viewing the two shoulders, for the purpose of discovering the deviation from aymetry, it gave an appearance on the affected side as if the glenoid cavity had been thrown forwards, and rendered, particularly preminent. The whole arm appeared shartar? particularily pred forterds, but separated from the body; the head of the bone could be distinctly felt upon the dorsum of the scapula, producing a considerable tumour, and forming the grand diagnostic mark of the nature of the injury. I raised the arm perpendicularly to the body, in the manner recommended for the reduction of such dis locations, but not being successful in returning the head of the bone into its place, and the attempt occasioning very considerable pain, I desisted, and proceeded in the following manner. The scapula being fixed, I made extension from the wrist in the direction of the displaced bone (without putting my foot on the axilla) for two or three minutes, while my friend Mr. J. Davison, surgeon, of Aln rick, then a pupil of Guy's, was directing the head of the bone forwards from the dorsum of the scapula, and in this way it readily slipped into its place.

Mr. Cooper attributed my want of success in reducing the dislocation in the way I at first attempted, to the want of strength on my part properly to raise the arm; and strongly recommends the perpendicular eleration, as the best mode in such cases for reducing the dislocated bone.

31, Norfolk Street, Jan. 9th, 1854.

\section{NOTES ON EPIDEMICAL DISEASES.} By WULIAM ADDISON, M.D., F.R.S.

$$
\text { ro. II. }
$$

IN PLOERZA, CHOLERA, CONTINUED FEVER, TYPHU8, $\triangle Q U R$, REMITTENT FEVER, DIAREHOA, DYBENTERY, BMAIT-POZ, GCARIET FEVER, MEASLES, HOOPING-COUGH.

\section{BNDEMIC АTMOSPHERES.}

Exhanatroxs arising from marshes, the low shores of livers and harbours, from jungles, and other uncultivated and undrained places, constitute a poison which produces fevers of various types and degrees of intensity. There are situations in hot climates in which these exhalations genorate a poison 80 intense, that a few inspirations of the air in which they are diffused is capable of producing death; and there are other situations in which a less highly concentrated poison accumulates, the inspiration of which for a short period produces a ferer capable of destroying life in a few hours.

That substances mixed or suspended in atmospheric air may be conveyed with it to the lungs, and immediately enter into the blood, any one may easily satisfy himself by passing through a recently painted room. The vapour of turpentine diffused through the room is transmitted to the lungs with the air which is breathed, and passing into the current of the cfrculation, will exhibit its effects in some of the fluid excretions of the body, even more rapidly than if it had been taken into the stomach.

Facts such as these help us to understand how disease may be produced and propagated through the medium of an infected atmosphere. Very striking offects from such a cause have been witnessed in the crews of ships. The health of the men has been perfectly good whilst at sea, but no sooner do they arrive in port than sickness, sometimes to a fearful extent, begins. On the other hand, sickness acquired in port diminishes, and fresh cases cesse to appear, on the ship again putting out to sea.

A fow years ago, the Centurion dropped her anchor in Bombay harbour, in the month of March, at which time the ship's company were in good health. A few days after, eighteen men were taken ill of fever in one night, and from that time, from eight to twelve men were daily added to the sick list, until the number amounted to 120 . In 1839 , fever of a very malignant kind appeared among the crew of the Vestal, then at anchor in Barbadoes. Fifty cases occurred in ten days; and there appearing but little prospect of the disease abating whilst the ship remained in port, she put to ses. On the fourth day after the divease 
We poweptibly mitigated, and it ceaced before she reached the Bermudas.

In tomperate climates, diseases from malaria, though lem covere and fatal, are not the less notorious. Marshy and swampy spots in low situations, whether on commons, near moods, or by road-sides, where they hardly attract notice, are productive of injurious miasms, though their notice, are productive of injurion their power insensible, except when houses happen to be erected in their vicinity. There are places without any marshes where ferers are almost annually prevalent, while other places in the vicinity are almost wholly or quite exempt. In certain houses family is rarely without some form of sickness, and families which before had been healthy have become the reverse on changing houses or situations; 80 , on the contrary, they have recovered health by change of residence; and many woody districts in Kent and Sussex are known to be productive of agues and remittent fevers; the same may be aid of some parts of Hampshire and Essex, as about Ipping Forest, for example. Meadows, too, which cannot be called marshy, are capable of originating endemic maladies. The meadow lands about Fontainbleau, at the junction of the Yonne and the Seine, are notorious for the fievre du pays; and all the alluvial tracts at the entrances, and cometimes at the exits, of the lakes of Switzerland, are well known sources of malarious diseases. It has been said that there can be no malaris on the banks of a running stream; and as far as mountain torrents are concerned, this is probably true : but where rivers slowly meander through low grounds, we must not trust to the mere motion of the water. There is ample evidence, that in England such streams as the Ouse and the Lea, and all others flowing with dificulty through fertile meadows wlth a flat vegetable margin, are productive of endemic maladies. In the second report of the sanitary commissioners, it is stated that marsh diseases prevail at times among the agricultural population of those parts of Kent and Essex bordering on the Thames.

"The insalubrity of undrained land is seen now in England," says the Registrar-General, "on comparing the mortality (2*45) of Ely, North Witchford, Whittlesey, and Wisbeach in Cambridgeshire, at the mouth of the Nene, with the mortality ( 1.80 to 1.40 per cent.) of the high parts of Surrey, Susser, North Devon, and Northumberland."

In 1849, Dr. Parkes made an analysis of the first twentyeight cases of cholera which occurred in and near London. The two first cases occurred simultaneously, one at Lambeth, the other at Chelsea; on the following day, a case appeared in Fleet Street, then one in the Justitia hulk, at Woolwich; and then three cases in the Dreadnought hospital ship, off Greenwich. At the moment we are penning these notes (October, 1853), cholera is sgain visiting the metropolis epidemically, and selecting its first victims along the banks of the Thames. In the return of the RegistrarGeneral for the week ending Saturday, October 8th, from a total of 66 deaths from cholers, 9 were in Bermondsey, 8 in Bouthwark, 6 in Lambeth, 5 in Wandsworth, and 6 in Botherhithe and Greenwich.

The form and severity of disease occasioned by malaria are in some proportion to the intensity of the sun's rays; it is by a consideration of the points of temperature that the relation of different kinds of fever becomes apparent. Under tropical heats, fevers are most violent, and assume the continued form; in a more temperate climate the remittent, and in colder countries the intermittent, are at least very usual types. That the miasm which occasions these disorders is of terrestrial origin, seems proved, for we do not find them prevailing among sailors out at sea, whatever may be the temperature under which they cruise. It is when they approach the coast, or land upon it, that they are attacked. Again, it has been observed that in malarious places, fevers abound more in hot and dry years than in those which are more temperate. In the higher grounds of the West Indies, agues occur; ss you descend, and the mean temperature increases, remittents are met with; and in the lowest and hottest parts, fover becomes continued.
$\Lambda$ very instructive fact of this kind has been related by Dr. Ferguson, in Antigua. The barrack was on an eminence, Monk's Hill, six hundred feet abore the level of the marshes. So pestiferous was the air of the marshes, that it often happened to a well seasoned soldier mounting the night-guard there in perfect health, to be seized with fever, and die within less than thirty hours; those at Monk's Hill having no fever of any kind. Seventeen artillerymen were stationed halfway down the hill. Every one of these men was attacked with remittent fever, of which one of them died. Thus, in the same place, malaria in the level plain caused the worst form of fever: at an elevation of three hundred feet, it gave rise to intermittent; and at the height of six hundred, its influence was scarcely felt at all.

It was long ago remarked by Dr. J. Hunter, that a difference of a few feet in height gives a comparative security to persons living in the same building: and the danger of sleeping on a ground floor has been noticed in the writings of lind and others. With respect to cholera, it has been found that the number and severity of the cases diminish in proportion to the altitude or level of the houses. In London, an elevation of some twenty or thirty feet lessens the per centage of deaths from this disease. It is therefore often a safe precaution to remove the sick from the lower to the higher apartments of the house, -2 more speedy and complete recovery having been found to follow.

$A$ moist and calm state of the air is favourable to the outbreak of endemic sickness. "Under certain atmospheric conditions," says Mr. Wagstaff, parochial surgeon, of Lambeth, "when I arose in the morning and found the atmosphere warm and moist, I could always foretel that there would be an increase of malarian disease of some sort." During the plague season in Egypt, the atmosphere is constantly charged with moisture; so much so, that the difference between the wet and the dry bulb thermometer is not more than two or three degrees; the average throughout the year being eight or ten degrees. Moreover, as a general rule, especially in hot climates, it is either at the commencement of the rainy season, or soon after its termination, that endemic disease most abounds. In the West Indies, for example, the last month of the rains, and the two which immediately follow, are generally sickly months.

On referring to the experience of cholera in this country, it appears that the great majority of seizures were between midnight and six in the morning. In Hamburgh, the attacks were 80 generally in the night, that when the epidemic was at its height, many persons were afraid to go to bed at all; and the same observation has been made with respect to plague when it prevails as an epidemic. Dr. Laidlaw states that in his own experience at Alezandria, during the prevalence of the plague in that city in 1835, eight-tenths of those who were attacked were seized during the night time. In the year 1766, two East Indiamen anchored off the Comora Islands; the crews were attacked by fever, and seventy of the number died. In this instance, the fever infected those of the crew only who slept at night on shore, and having gone through them it ceased. Mr. Shields, in his report of the endemic fever of Batavia, says, "Almost every person who slept only a single night at Edam died. No ill effects were experienced from going on shore in the day time, or among the stck at the hospital. I myself regularly visited the hospital at Edam every day with perfect impunity, till one night I stayed rather late, in consequence of which I was three days afterwards seized with fever." Dr. Lind says, "the nature of an unhealthy shore is such, that no sooner are the sunbeams withdrawn, than the air in the most sultry climates feels raw, damp, and chilly; and it has been recorded of persons seated in the evening air after sunset, that they have suddenly felt faint, giddy, and sick, and obliged to retire ;" these symptoms warning them of the presence of a terrestrial miasm. Experience then in all climates is decisive that there are local sources of sickness arising from terrestrial effluvia, and that their potency is increased by warmth and by moisture, succeeded by cold,-by a low situation, and the night season. 


\section{But let us recapitulate the facts :-}

Ferers arising from terrestrial effuvia are more severe and fatal in hot than in colder countries. Their onset, form, and characters, bear some proportion to the intensity of the sun's rays. They are for the most part limited to level plains, marshes, low damp situations, jungles on the shore, and the banks of rivers. Their attack is usually referred to the night season; and an elevation, sometimes of only a few feet, has been found a security against them. Now, terrestrial effluvia must be as abundant in the atmoophere during the day as at night. How is it then that the diseases they occasion are referred particularly to low situations, limited areas, and the night season? Under what general law then can these facts be arranged?

All substances freely exposed to the heat of the sun give off effluvia. This is so obvious a truth with respect to those which have odour, that nothing need be said to substantiate it. There are other substances quite inodorous when dry: but which give out when moist and warm a strong scent. A stone or piece of earth will give out an effluvium perceptible by the smell when gently breathed upon. Woollen clothes may have no smell when quite dry, but when wet and brought into a warm room they smell strongly. Epsom salts, sulphate of zinc, and other salts, when dissolved in water quite cold, have but little or no perceptible odour; when, however, they are put into solution with boiling water, they give out a strong effluvium. The ordinary operations of cooking furnish numerous similar facts. Observe, too, the peculiar effluvia arising with the vapour when hot iron or coals are quenched with water. These instances show that warmth and moisture facilitate the extrication of an effluvium from bodies in which nothing of a volatile nature is perceptible whilst they are perfectly dry: the effluvium or odour escapes in conjunction with aqueous vapour, and its sensible qualities increase in proportion as temperature increases. Every one must at some time or other have been sensible of the powerful effluvia given out on all sides, when the first rain after a dry period meets the heated soil. And it has been noticed by those who have attended to the matter, that the effuria are stronger in proportion to the difference between the heated surface of the ground and the cooler superincumbent air. Again, all are aware of the strength of odours in a still atmosphere after a hot day when dew is beginning to appear on the grass, as though volatile matter carried off by the evaporation of moisture were made sensible in some especial manner, by condensation of vapour. When the moisture which condenses on the walls and windows of a room in which large numbers of persons are assembled, is examined, it has been found to be impregnated with animal matter.

In the example of the heated saline solutions, aqueous vapour, with its associated effluvium issuing from the hot liquid, is immediately condensed by the colder air, and hence the readiness with which the presence of the efluvium is at that moment detected.

Evaporation takes place from every part of the earth's surface, and the rate or quantity of aqueous vapour disengaged is in proportion to the temperature. When the ground is hot and dry, evaporation, upon the first fall of rain, is prodigious.

From the instances which have just been stated, we must conclude, that terrestrial niasms are diffused through the atmosphere in combination with the vapour exhaled by evaporation; and that quantity or potency increases in proportion as the temperature of the surfaces from which they arise increases. The miasm is dissolved by the vapour, and vapour is dissolved by the air. These are effects of the sun's rays.

The researches of Leslie, Romford, and others, have shown that different bodies have different powers of radiating caloric, and that the nature of the surface has an important influence over the process. This produces corresponding variations in the rate of cooling; those surfaces which radiate heat most rapidly becoming cold much the soonest.
When the ren descends below the harison, overy portien of the earth's surface cools by radiation; and s retuction in the temperature of the superincumbent atmosphere necescarily ensues. But, as this radiating property is very different in different surfaces, and in difierent situations, 8 great variations are occasioned in contiguous places, not only in the temperature of the air, but also in the amount of condensation of vapour; more mist, more fog, or dew, appearing where radiation is greatest. Those are the effects of the night season.

Dr. Wells frequently observed the temperature of 2 grass meadow at night to be several degrees below that of the air some feet abore it; and thermometers, placed in different situations upon the ground, were found to mark very different temperatures, the greatest amount of der appearing where the cold was greatest. On clear and still nights, a difference of thirty degrees Fahr. has boen noticed between the temperature of good radiating surfaces and that of the air some height above them. More frequently the ground has been observed ten degrees colder than the air twenty or thirty foet above it: and it is thus that the leaves of trees have been found quite dry when the grass of an adjacent meadow is loaded with dew. "I had often sniled," says Dr. Wells, "in the pride of half knowledge, at the means frequently employed by gardeners to protect tender plants from cold, as it appeared to me impossible that a thin mat, or any such flimsy substance, could prevent them from attaining the temperature of the atmosphere, by which alone I thought them liable to be injured; but when I learnt that bodies on the surface of the earth become often colder than the air, by radiating their heat to the hearens, I perceived immediately a just reason for the practice which I had before deemed useless. Being desirous, howerer, of acquiring some precise information on this subject, I fixed perpendicularly, in the earth of a grass-plat, four small sticks, and over their upper extremities, which were six inches above the grass, I drew tightly a very thin cambric handkerchief. In this disposition of things, therefore, nothing existed to prevent the free passage of air from the exposed grass to that which was sheltered, except the four small sticks; and there was nothing to radiate downwards to the latter grass, except the cambric handkerchief. The sheltererl grass, however, was found five degrees Fahr., or more, warmer than the unsheltered. One night, the fully exposed grass was eleven degrees calder than the air; but the sheltered grass was only three degrees colder." A canopy of clouds, ralls, buildings, or any other shelter from the aspect of the open sky, act upon the same principle, and in the same way.

The question, whether, on any particular night, condensation will or will not occur, and the period that may elapse after sunset before it takes place, is determined by the relation between the temperature of the air and the temperature of the dew-point. This is constantly varying. When the interval between them is large (ten or twelve degrees), some time is required for the heat of the air to fall to the dew-point, condensation is delayed, and the air is said to be dry. On the other hand, when the interval is small (one or two degrees only), condensation occurs immediately after sunset, the air is said to be damp, and those surfaces which radiate heat quickly become soon evident, especially should the atmosphere be freo from cloud, and without wind. The banks of rivers and lakes, open plains, marshes, meadows, and low situations, are wotted with dew, or the first to be shrouded in mist or fog; and they are sensibly colder than other places.

Thus it is found that the conditions under which malarious diseases arise accord with the laws of evaporation and terrestrial radiation; and we conclude, that the precipitation of vapour-mist, haze, fog, or dew-may be taken as evidence of the concentration of the poison. Condensetion of vapour commences; and it appears a corsequence of this, that associated miasms, left alone, begin to show their proper qualities. Not that at all times noxious effuria pass into the air, so as to be made sensible whenever der or fog appears; but that when they do exist, quantity is do- 
crumined by heat and eraporation, and poisonous qualitios brought out when the asociated rapour is condensed.

The peculiar properties of many bodies disappear in combination. There is nothing, therefore, to negative the aupposition that the hurtful qualities of terrestrial effluvia may appear only when their union with aqueous vapour is docompoeed: and the theory accounts for the comparative abeance of noxious qualities in the day time. It is not more difficult to conceive the irregular and unequal dispersion of hurtful exhalations over limited spots or tracts of country, occasioned by terrestrial radiation, than to be convinced of similar inequalities in the distribution of clouds and fog. And this would explain the immunity afforded by erevion. Moreover, sundry phenomena in relation to diseases have been attributed to the light of the moon; but, when the moon shines, the atmosphere must be free of clonds, and a clear atmosphere is the most farourable to the specific influences of radiation.

Maidstone, Jan. 1854.

\section{[To be continued.]}

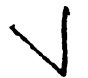

\section{CLTNICAL LECTURES, DELIVERED AT THE LOCK HOSPITAL, LONDON.}

By HENRY LEE, Esq., F.R.C.S., Surgeon to the Hospital.

No. II. (Nov. 15 Tr, 1853.)

Ganturmex:-In my last lecture, I brought under your notice three forms of inflammation produced by the direct contact of syphilitic matter. In one of these, I mentioned that the action terminates directly in the death of the infected part; and I pointed out that, inasmuch as the syphilitic virus requires a living nidus for its development, the death of the part in which it is placed involves the destruction of the virus itself. The time during which the virus may remain in a part without producing any but a local cetion is at lesst four or five days. If within this time the part be destroyed by caustic, or if it slough spontaneously, a simple ulcer only will remain. There will then be no longer any local specific action; the inguinal glands will not participate in the disease; and the constitution will not become affected. If, however, the sloughing is produced after either of the other forms of inflammation have existed, then it will not interfere with the usual course of the disease. but may be regarded as an accidental complication.

Of this first effect of inflammation, we have examples in cases in which parts have been purposely inoculated, and the inoculation has been destroyed by the application of some caustic. I may mention here, that, in performing this operation, it is well to use the nitric acid or the potassa cum calce, in order to destroy the inoculated part. The action of the nitrate of silver is superficial, and there is reason to believe that it sometimes remores a superficial layer of the skin, without penetrating to the same depth as the point of the lancet.

The second form of inflammation produced by the direct contact of syphilitic matter, which I mentioned, was that in which the action terminated in acute ulceration. In this affection, the disease is not confined to the part to which the poison is applied; it may be traced in the clearest way along the absorbent vessels, generally on one side only. In any part of its course, the poison may inoculate the vessel in which it is contained, and may produce a fresh syphilitic sore, the secretion of which may again be inoculated. It usually happens, however, that the inguinal gland in which the absorbent vessels terminate is the part affected. Here alone, in the great majority of cases, does the poison exercise its influence upon the absorbent system; but that the poison actually passes, as such, through the absorbent vessels, we have abundant proof in the occasional formation of specific abscesses in the course of those ressels. This circumstance has actually occurred in the case of the patient to which I have directed your attention, as present- ing a well marked instance of this disease. Between the open bubo in the groin, and the inflamed and irregularly ulcerated surface at the seat of the primary disease, a small abscess has formed. This presents tumid and irritable edges; and I cannot doubt that an inoculable pus might have boen derived from it. We can then distinctly trace the entrance of the syphilitic poison into the lymphatic vessels, and from them into the absorbent glands in which these vessels terminate. The actual existence of the virus in any part of this course may be demonstrated by experiments, which have been far too often repeated to require any additional confirmation. Arrived at this point in its course, on its way apparently towards the thoracic duct, and from there to the general circulation, what becomes of it? A very wonderful change is here brought about. The specific virulent poison, which before was liable to contaminate every living part that it came in contact with, cannot nuw be traced beyond this point. The absorbent vessels between the inflamed gland and the thoracic duct do not ulcerate or suppurate; the glands into which they empty themselves do not become enlarged or inflamed. The influence of the poison is here then gone. Beyond the glands first in order, the fluids which the absorbent vessels contain are bland and harmless, incapable of being inoculated, or of infecting any part with which they come in contact. What then has become of the poison? We find it in the ressels going into the inflamed absorbent glands, but we do not find it in the vessels which proceed from those glands. In a certain number of cases, no doubt, the poison is in great measure discharged in the suppuration to which its presence gives rise. But, when we consider the exceedingly minute quantity of an animal poison that is capable of producing its specific action on a part, this explanation is not sufficient. Some of the fluid or particles which enter the gland must, in some form or other, we should think, pass through it, whether it suppurate or not. Eren although we should suppose that the inflammation produced in the gland entirely obstructed its channels, still, before such obstruction could take place, some fluid would surely have time to pass; and this, if its quality remained unchanged, would be abundantly sufficient to inoculate any part with which it came in contact, or to infect tho general system.

A somewhat analogous circumstance is observed in cases of cancer. The first set of glands which the absorbent vessels, coming from the seat of the disease, reach, aie alone inoculated. The glands second in order, nearer the centre of the circulation, may be enlarged, but they seldom are the seat of malignant disease. Four weeks ago, a patient died in this hospital with obstinate chronic enlargement of the skin on the right labium. My friend Dr. Druitt, who carefully examined the tumour, assures me that the substance of the skin and of the subcutaneous areolar tissue was infiltrated with cells which he could in no way distinguish from cancer cells. Shortly before her death, the inguinal glands upon both sides suppurated; but, upon examining the body afterwards, we could find no affection at all of the glands within the abdomen. The facts presented by such cases I wish to distinguish from any theoretical explanation of them; yet, must we attempt to give a rational explanation of the cause or connexion of the circunstances which we observe, such an explat.: tion will lead us to further inquiries into similar actions elsewhere, which may throw some light upon our inquiries, and perhaps, in their turn, be illustrated by them.

Independently of the essential nature of the affection, more glands will be found to be affected in malignant disease than in syphilis. This may probally be accounted for by the relative extent of parts affected in the two cases. In the first, the absorbent vessels derived from different parts of the disease may communicate the affection to several absorbent glands; in the second, the extent of surface involved is usually very limited, and the absorbent vessels leading from it are therefore also limited in number.

If we reflect upon the different ways in which foreign substances can be taken into the living body, we shall find that every such way is furnished with certain sentinels or 